\title{
Expression of Genes Encoding Late Nodulins Characterized by a Putative Signal Peptide and Conserved Cysteine Residues Is Reduced in Ineffective Pea Nodules
}

\author{
Takashi Kato, ${ }^{1}$ Kazuya Kawashima, ${ }^{1}$ Masami Miwa, ${ }^{1}$ Yoshifumi Mimura, ${ }^{1}$ Masanori Tamaoki, ${ }^{1}$ \\ Hiroshi Kouchi, ${ }^{2}$ and Norio Suganuma ${ }^{1}$ \\ ${ }^{1}$ Department of Life Science, Aichi University of Education, Kariya, Aichi 448-8542, Japan; ${ }^{2}$ Department of Plant \\ Physiology, National Institute of Agrobiological Sciences, Tsukuba, Ibaraki 305-8602, Japan
}

Submitted 25 July 2001. Accepted 27 October 2001.

Five nodulin genes, PsN1, PsN6, PsN314, PsN335, and PsN466, with reduced expression in ineffective nodules on the pea (Pisum sativum) mutant E135 (sym13) were characterized. They encode small polypeptides containing a putative signal peptide and conserved cysteine residues and show homology to the nodulins PsENOD3/14 and PsNOD6. For each gene, multiple bands were detected by genomic Southern analysis. Northern analysis showed that all five genes were expressed exclusively in nodules and that their temporal expression patterns were similar to that of the leghemoglobin (Lb) gene during nodule development. Their transcripts were localized predominantly from the interzone II-III to the distal part of nitrogen-fixing zone III in effective nodules, resembling the $\mathrm{Lb}$ gene. However, transcripts in ineffective E135 nodules were localized in narrower regions than those in the effective nodules. These results indicate that these nodulins are abundant in pea nodules and that their successive expression during nodule development is associated with nitrogen-fixing activity.

Legume and Rhizobium symbiosis is established by a coordinated expression of genes of both partners. Successful symbiosis involves several complex processes represented by root hair curling, infection thread formation, cortical cell division, nodule initiation, and nitrogen fixation, indicating that a number of plant and bacterial genes participate in the symbiotic association. Plant genes expressed exclusively in nodules, termed nodulin genes (van Kammen 1984), are involved in the development of nodules, and dozens of nodulin genes have been isolated to date. Nodulins are divided into early and late nodulins, depending on the time of appearance during nodule organo-

Corresponding author: Norio Suganuma; Telephone: +81-566-26-2647; Fax: +81-566-26-2310; E-mail: nsuganum@ auecc.aichi-edu.ac.jp

Current address of M. Tamaoki: National Institute for Environmental Studies, Tsukuba, Ibaraki 305-0053, Japan.

Nucleotide sequence data reported are available in the Genbank, EMBL, and DDBJ databases under the accession numbers AB059549 (PsN1), AB059550 (PsN6), AB059551 (PsN314), AB059552 (PsN335), and AB059553 (PsN466). genesis and development (Nap and Bisseling 1990). Some late nodulins have been identified as leghemoglobin (Lb) (Baulcombe and Verma 1978) and enzymes involved in carbon and nitrogen metabolism such as uricase (Bergmann et al. 1983), glutamine synthetase (Gebhardt et al. 1986), and sucrose synthase (Thummler and Verma 1987). Some are present in the peribacteroid membrane surrounding the microsymbiont, and a major protein component, nodulin 26 , appears to be a member of the aquaporin water channel family (Rivers et al. 1997). However, the exact functions of the early nodulins and most of the late nodulins remain unclear.

Bacterial mutants that form ineffective nodules arrested at various stages of nodule development have been used to profile the expression of nodulin genes (Dunn et al. 1988; Govers et al. 1987; Jiménez-Zurdo et al. 2000; Padilla et al. 1991; Sengupta-Gopalan et al. 1986). Those analyses appeared to show a correlation of nodulin gene expression with the different stages of nodule development and provide valuable information concerning the functions of nodulin genes. We previously isolated a set of nodulin genes from pea nodules by a subtraction procedure and compared their expression in effective nodules with their expression in ineffective nodules induced on the pea mutant E135 (sym13) (Suganuma et al. 1995). The E135 mutant forms ineffective nodules in which nitrogenase proteins are synthesized, but nitrogen-fixing activity is lacking (Suganuma et al. 1998). In this type of ineffective nodule, all the nodulin genes isolated are expressed, but the expression of some is considerably reduced, suggesting that their functions are related to nitrogen-fixing activity.

One of the nodulin genes with reduced expression in ineffective E135 nodules was PsN5, a Lb gene (Suganuma et al. 1995). Further characterization of PsN5 showed that this type of Lb has a higher oxygen-binding affinity than another type of Lb encoded by PsN120 and is expressed throughout the central tissue of effective nodules (Kawashima et al. 2001). These results suggested that the PsN5 type of Lb plays a greater role in nitrogen fixation and oxygen consumption of bacteroids by rapid transfer of oxygen to the bacteroids. In this paper, we describe the primary structures of the remaining nodulin genes, PsN1, PsN6, PsN314, PsN335, and PsN466, with reduced expression in ineffective E135 nodules and their temporal and spatial expression patterns during nodule development. Possible functions of these nodulin genes are discussed with respect to nitrogen-fixing activity. 
Table 1. Identification and homology of pea nodulin genes isolated by a subtraction procedure

\begin{tabular}{|c|c|c|}
\hline Clone & Identification & Homology \\
\hline \multicolumn{3}{|c|}{ Clones expressed normally in E135 nodules } \\
\hline PsN2 & Early nodulin ENOD2 & \\
\hline PsN3(89) & Root nodule lectin PsNlec1 & \\
\hline PsN8 & & Vicia faba late nodulin Nvf-28 \\
\hline PsN12 & & V. faba glycine-rich protein VfNOD-GRP1 \\
\hline PsN35 & Early nodulin ENOD14 & \\
\hline PsN120 & Leghemoglobin & \\
\hline PsN122 & & V. faba early nodulin VfENOD-GRP5 \\
\hline PsN156 & Early nodulin ENOD3 & \\
\hline PsN374 & Early nodulin ENOD7 & \\
\hline \multicolumn{3}{|c|}{ Clones with reduced expression in E135 nodules } \\
\hline PsN1 & & Pisum sativum nodulin ENOD3/14, NOD6 \\
\hline PsN5 (161) & Leghemoglobin & \\
\hline PsN6(10) & & $P$. sativum nodulin ENOD3/14, NOD6 \\
\hline PsN314 & & $P$. sativum nodulin ENOD3/14, NOD6 \\
\hline PsN335 & & P. sativum nodulin ENOD3/14, NOD6 \\
\hline PsN466 & & $P$. sativum nodulin ENOD3/14, NOD6 \\
\hline
\end{tabular}

PsENOD3
PsENOD14
PsNOD6
PsN1
PsN6
PsN314
PsN335
PsN466
VfNOD-CCP1
VfNOD-CCP2
VfNOD-CCP3
VfNOD-CCP4
VfNOD-CCP5

PsENOD3

PsENOD14

PsNOD6

PsN1

PsN6

PsN314

PsN335

PsN466

$V$ FNOD-CCP 1

$V+N O D-C C P 2$

$V+N O D-C C P 3$

$V+N O D-C C P 4$

$V f N O D-C C P 5$

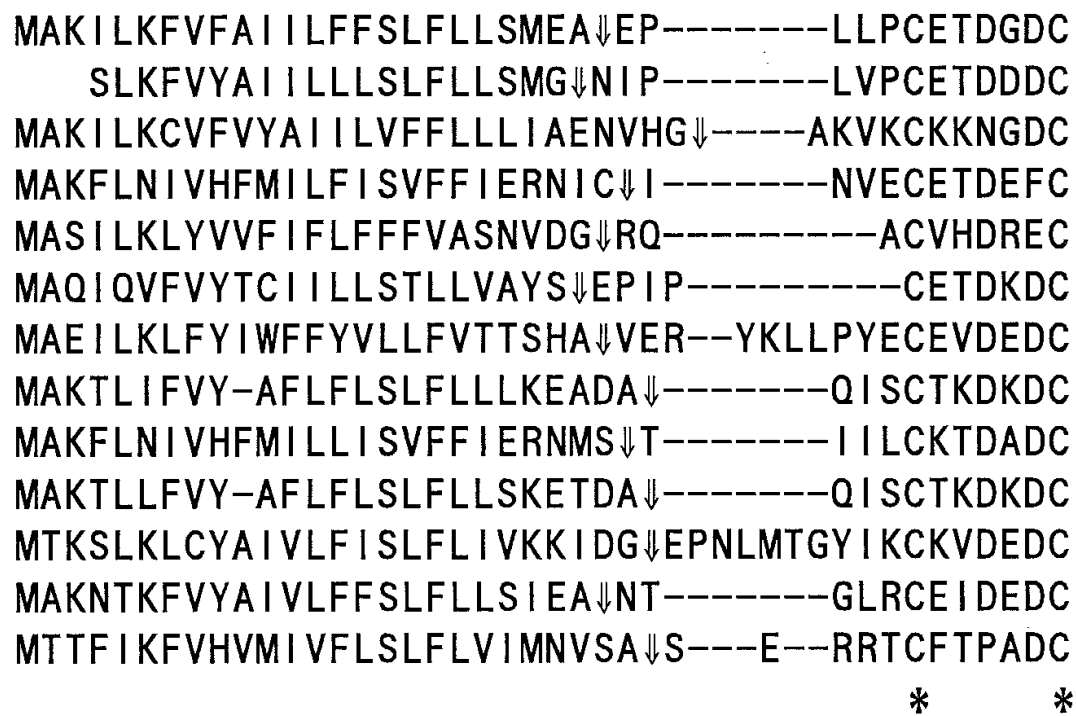

PLKP I IETTPMI SLHYMC I DKECVLFREVLOTP------ 69

PMEMS I PS I PNKLLFFMCWEKECVYRRW------------ 61

PKLPHMFP-----I I YRCYOOECTLVRVLDS--------- 65

QETFPNINK--S-HI VKC I DNLCQFLGKKEVGVNT----- 68

KCPGHPVS--------RCVKGFCRCYTFPAIPSFKGMNKY 66

PWE I FPL-------VMKC I NKFCEYKIVL----------- 56

PRY I HHP------Q I MKC INLFCR I VYOD----------- 64

PD I SHLK-----I L I FKC INE I CEAVKPDAE--------- 61

I KKDLSN-------DWKC I ENQCKFVKVAPAFGGTE---- 65

PDI SHLK-----I L I FKC INN I CEAVKPDAAE-------- 62

PTLLVMS-------AYKCIDNLCKLFRLPF---------- 66

PRDVT ILEK--LSYI YKCFDKEC I VTEAPF---------- 64

PTSDCEP-----PSRPFCAFKYCICG------------- 59

Fig. 1. Alignment of the deduced amino acid sequences of PsN1, PsN6, PsN314, PsN335, PsN466, the early nodulins PsNENOD3 (P25225) and PsENOD14 (P26415), the late nodulin PsNOD6 (S43336), and Vicia faba cysteine cluster proteins, CCP1 (AJ243462), CCP2 (AJ243463), CCP3 (AJ243464), CCP4 (AJ243465), and CCP5 (AJ243466). Multiple sequence alignment was carried out using the 'CLUSTAL W' program. Cleavage sites for the putative signal peptides marked by vertical arrows were predicted using the 'SignalP' program. Conserved cysteine residues are marked by asterisks. 


\section{RESULTS}

Primary structure

of PsN1, PsN6, PsN314, PsN335, and PsN466.

The nucleotide sequences of nodulin clones that had been isolated by a subtraction procedure (Suganuma et al. 1995) were determined. Previously, PsN2 was identified as ENOD2, and PsN5 and PsN120 were identified as distinct types of Lb genes (Suganuma et al. 1995; Kawashima et al. 2001). In the present study, a BLAST search (Altschul et al. 1997) revealed that $P s N 3, P s N 35, P s N 156$, and $P s N 374$ were identified as PsNlec1 (Kardailsky et al. 1996), ENOD14, ENOD3 (Scheres et al. 1990), and ENOD7 (Kozik et al. 1996), respectively (Table 1). PsN89 was identical to $P s N 3$, and $P s N 161$ was identical to PsN5. Furthermore, PsN8, PsN12, and PsN122 were homologous to $N v f-28$ (Küster et al. 1994), VfNOD-GRP1, and VfENOD-GRP5 (Schröder et al. 1997), respectively. However, five nodulin clones, $P s N 1, P s N 6$ (identical to PsN10), PsN314, $P s N 335$, and $P s N 466$, with reduced expression in ineffective E135 nodules compared with their expression in effective nodules, were so short in sequence that significant homology to any genes was not detected by BLAST search. Thus, these five cDNA clones containing complete protein-coding regions were re-screened from a nodule cDNA library or prepared by $5^{\prime}$ RACE reactions.

Sequence analysis of $P s N 1, P s N 6, P s N 314, P s N 335$, and PsN466 cDNAs indicated that they all encode small polypeptides characterized by the presence of a putative signal peptide at their N-termini and two pairs of cysteine clusters with common structures of Cys-X5-Cys and Cys- 44 -Cys (Fig. 1). The same structures were previously found for pea early nodulin
PsENOD3/14 (Scheres et al. 1990), late nodulin PsNOD6 (Kardailsky et al. 1993), and Vicia faba late nodulins designated as cysteine cluster proteins (CCPs) (Frühling et al. 2000). Thus, we postulate that these nodulins belong to gene families with closely related functions. However, sequence similarities of these nodulins other than signal peptides and cysteine clusters were low relative to each other, except for the case of $P s N 466$ versus VfNOD-CCP2. Deduced amino acid sequences of $P S N 466$ and VfNOD-CCP2 showed $91.9 \%$ identity, whereas sequence identities among the others ranged from 16.4 to $53.6 \%$.

Southern blot analysis of pea genomic DNA with cDNA probes for these five nodulins gave multiple bands (Fig. 2). Rescreening of a nodule cDNA library and $5^{\prime}$ RACE screening revealed the presence of two to four distinct mRNA species with a few base pair changes for PsN1, PsN314, PsN335, and PsN466 in nodules (data not shown). These results strongly suggest that each of these nodulins forms small multigene families.

\section{Temporal and spatial expression patterns.}

Transcripts of $P s N 1, P s N 6, P_{s N} 314, P_{s N} 335$, and $P s N 466$ were detected only in nodules (Fig. 3). Their temporal expression patterns were essentially similar to those of the Lb gene (Fig. 4). PsN6 transcripts appeared most abundantly at 12 days but, following an increase of the amounts of the transcripts, was not as remarkable as those of the Lb gene, $P s N 1, P s N 314$, and $P s N 335$. On the other hand, the expression of PsN466 in 12-day-old nodules was hardly detectable. These results showed that $P s N 6$ is expressed concomitantly with, or slightly earlier than, the Lb gene, PsN1, PsN314, and PsN335, while PsN466 appears later than those genes.

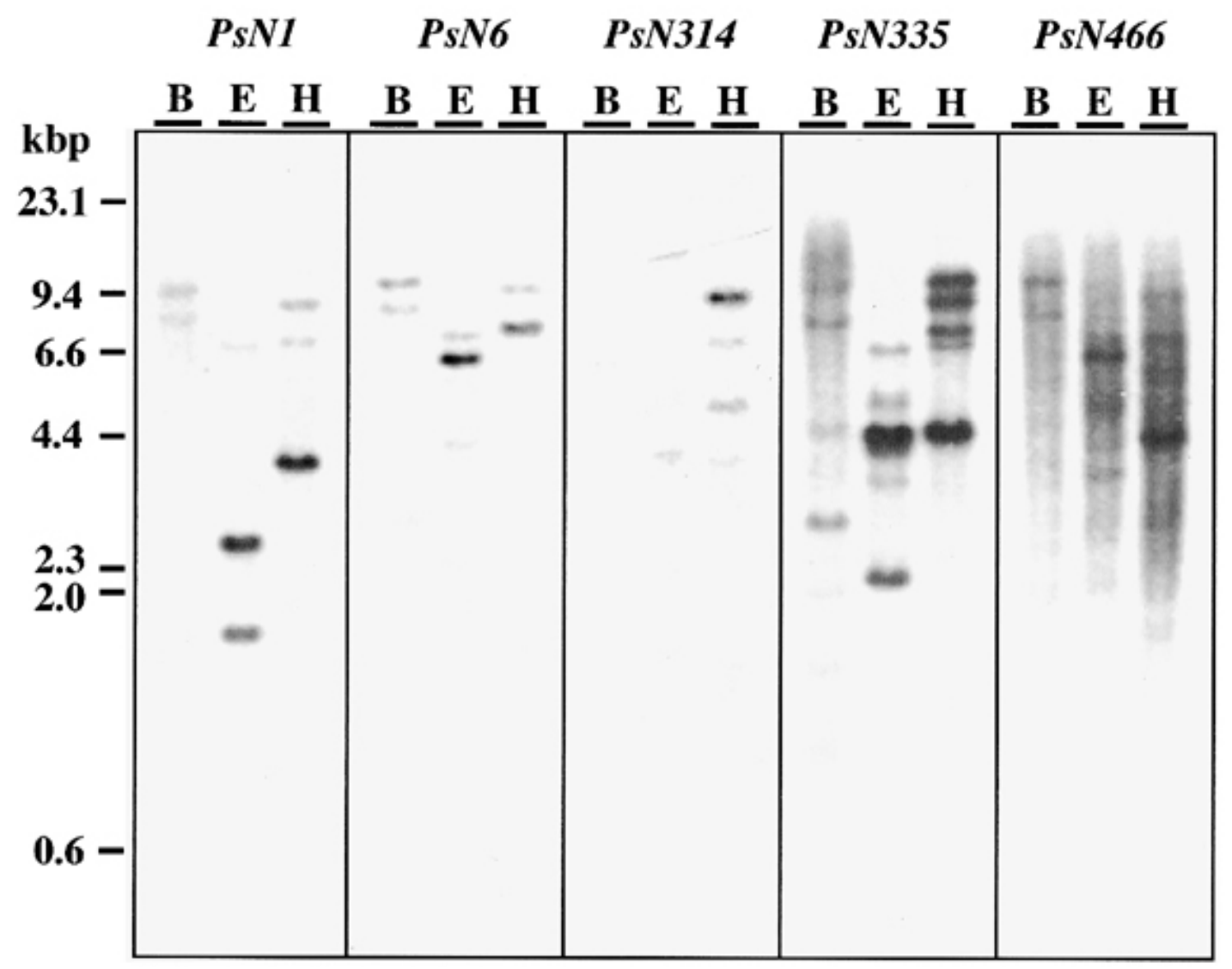

Fig. 2. Genomic Southern blot analysis of genes for PsN1, PsN6, PsN314, PsN335, and PsN466. Genomic DNA was isolated from leaves of 3-week-old cv. Sparkle plants. Genomic DNA $(10 \mu \mathrm{g})$ was restricted with BamHI (B), EcoRI (E), and HindIII (H), fractionated on a $0.8 \%$ (wt/vol) agarose gel, transferred to a nylon membrane, and hybridized with radiolabeled probes. 
Transcripts of PsN1, PsN6, PsN314, PsN335, and PsN466 were localized predominantly from the interzone II-III to the distal part of nitrogen-fixing zone III in the effective nodules, resembling the Lb gene (Fig. 5). Furthermore, consistent with the results of the temporal expression patterns, transcripts of PsN6 were also detected in the pre-fixing zone II, and the beginning of expression of $P s N 466$ was more proximal compared with those of the Lb gene, PsN1, PsN314, and PsN335. However, in ineffective E135 nodules, expression regions were narrower than were those in the effective nodules (Fig. 6). In particular, hybridization signals with $P s N 466$ were very faint. In contrast, the expression of ENOD12, ENOD14, and Lb genes in the ineffective nodules was almost identical to that in the effective nodules. Transcripts of PsN1, PsN6, PsN314, PsN335, and $P s N 466$, as well as those of the Lb gene, in both effective and ineffective nodules were detectable in the infected cells but not in the uninfected cells (Fig. 7). In Figure 7, only the results of $P s N 1$ are shown because results of the remaining genes were identical to those of $P s N 1$.

\section{DISCUSSION}

Fifteen pea nodulin clones that had been isolated by a subtraction procedure were identified (Table 1). Of these clones, expression of six genes was considerably reduced in ineffective E135 nodules compared with their expression in effective cv. Sparkle nodules (Suganuma et al. 1995). Nodules induced on the pea mutant E135 lack nitrogenase activity, whereas organogenesis and morphology of the E135 nodules are the same as those of cv. Sparkle nodules (Kneen et al. 1990; Suganuma et al. 1998). Thus, differences in the expression of these nodulin genes between effective nodules and ineffective E135 nodules appear to represent whether functions of these genes are related to nitrogenase activity. Early nodulins are predicted to be involved in rhizobial infection or nodule initiation (Nap and

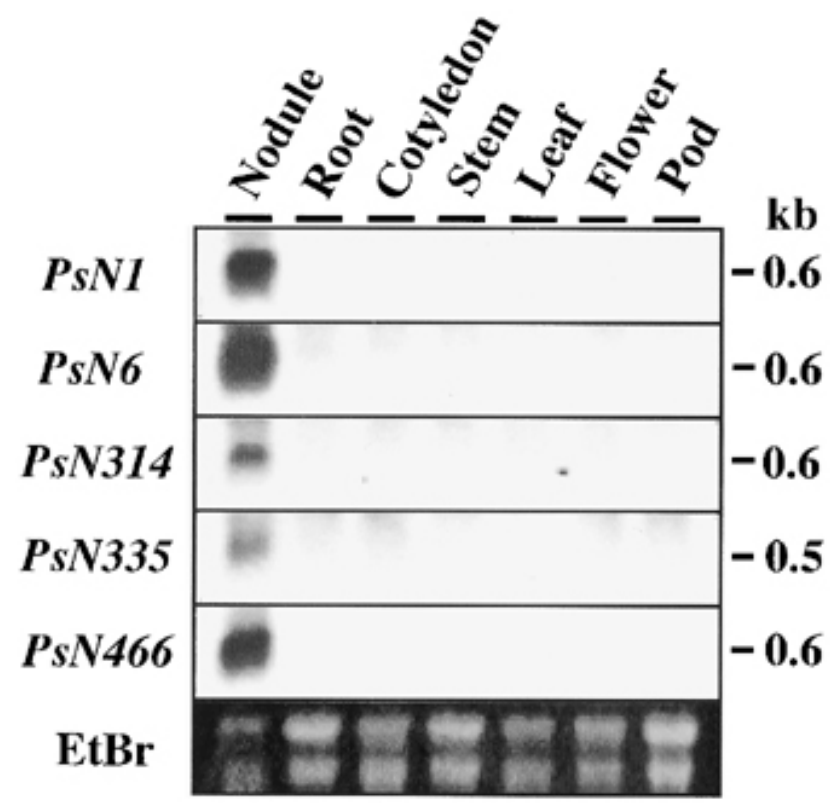

Fig. 3. Northern blot analysis of mRNA for PsN1, PsN6, PsN314, $P s N 335$, and PsN466 in the total RNA isolated from each tissue of cv. Sparkle plants. Nodules, roots, stems, and leaves were harvested from 5week-old plants, and flowers and pods were harvested from 6-week-old plants. Cotyledons were obtained from 1-week-old seedlings. Each sample of total RNA $(10 \mu \mathrm{g})$ was subjected to electrophoresis on a $1.25 \%$ (wt/vol) agarose gel that contained formaldehyde, transferred to a nylon membrane, and hybridized with radiolabeled probes. The rRNA samples stained with ethidium bromide (EtBr) are shown as controls.
Bisseling 1990). Expression of a number of early nodulin genes such as ENOD2, ENOD3, ENOD7, ENOD14, and homolog VfENOD-GRP5 were not affected in ineffective E135 nodules. Late nodulins, PsNLEC1 and VfNOD-GRP1, which are proposed to be components of symbiosomes and of plant cell walls respectively, (Kardailsky et al. 1996; Schröder et al. 1997) were also expressed in ineffective E135 nodules at levels comparable to levels in effective nodules. Since ineffective E135 nodules are morphologically similar to the effective nodules in the early stages of nodule development (Kneen et al. 1990), it is not surprising that nodulins potentially involved in nodule organogenesis and structure are expressed normally in the ineffective nodules. Kardailsky and associates (1996) also showed that the spatial expression pattern of PsNlecl in ineffective E135 nodules is similar to that in effective nodules. The late Nvf-28 nodulin is characterized by two types of amino acid repeats flanked by unique amino acid sequence termini, but its function is unclear (Küster et al. 1994). Our results suggest that such nodulins are not associated with nitrogenase activity.

In contrast, roles of nodulin genes whose expression is reduced in ineffective E135 nodules are presumed to be closely associated with nitrogen-fixing activity. Although the expression of six of the nodulin genes is reduced in ineffective E135

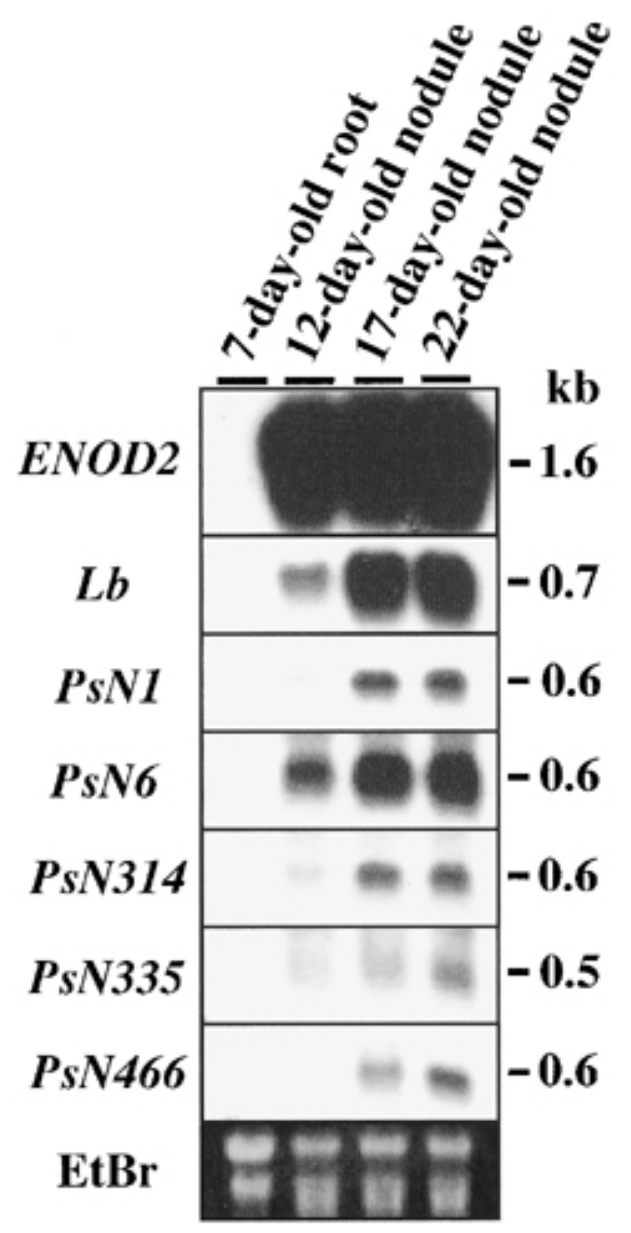

Fig. 4. Northern blot analysis of mRNA for PsN1, PsN6, PsN314, $P s N 335$, and $P s N 466$ in the total RNA isolated from uninoculated roots and effective cv. Sparkle nodules harvested at different days after sowing. For reference, the ENOD2 was used as the early nodulin gene and the leghemoglobin $(\mathrm{Lb})$ as the late nodulin gene, respectively. Each sample of total RNA $(10 \mu \mathrm{g})$ was subjected to electrophoresis on a $1.25 \%$ (wt/vol) agarose gel that contained formaldehyde, transferred to a nylon membrane, and hybridized with radiolabeled probes. The rRNA samples stained with ethidium bromide $(\mathrm{EtBr})$ are shown as controls. 
nodules, it was found that they belong to two groups of nodulin genes (Table 1). One, PsN5, is the Lb gene, which has a higher oxygen-binding affinity and is expressed in whole central tissue of the effective nodules (Kawashima et al. 2001). All the others were predicted to encode small polypeptides that contain a putative signal peptide and two pairs of cysteine clusters, such as Cys- $\mathrm{X}_{5}-\mathrm{Cys}$ and $\mathrm{Cys}-\mathrm{X}_{4}-\mathrm{Cys}$ (Fig. 1). They were confirmed to be genuine nodulin genes (Fig. 3). The predicted proteins of $P_{s N 1}$, PsN6, $P_{s N} 314, P_{s N} 335$, and $P_{s N 466}$ are structurally homologous to early nodulin ENOD3/14 (Scheres et al. 1990), but according to their temporal and spatial expression patterns (Figs. 4 and 5), they are categorized as late nodulin genes along with another homologous gene, PsNOD6 (Kardailsky et al. 1993). Govers and associates (1987) used differential hybridization to screen several nodulin cDNA clones from pea nodules. In addition to PSNOD6, they isolated $P S N O D 10$ and $P S N O D 14$, whose in vitro translation products are estimated to be small polypeptides similar to PSNOD6. Therefore, it is possible that both PSNOD10 and PsNOD14 belong to the same group, although their primary structures remain unpublished. They further showed that mRNA levels of those three genes are decreased in the ineffective nodules induced by Rhizobium mutants. In the present study, we could not isolate the gene corresponding to PsNOD6, though it is

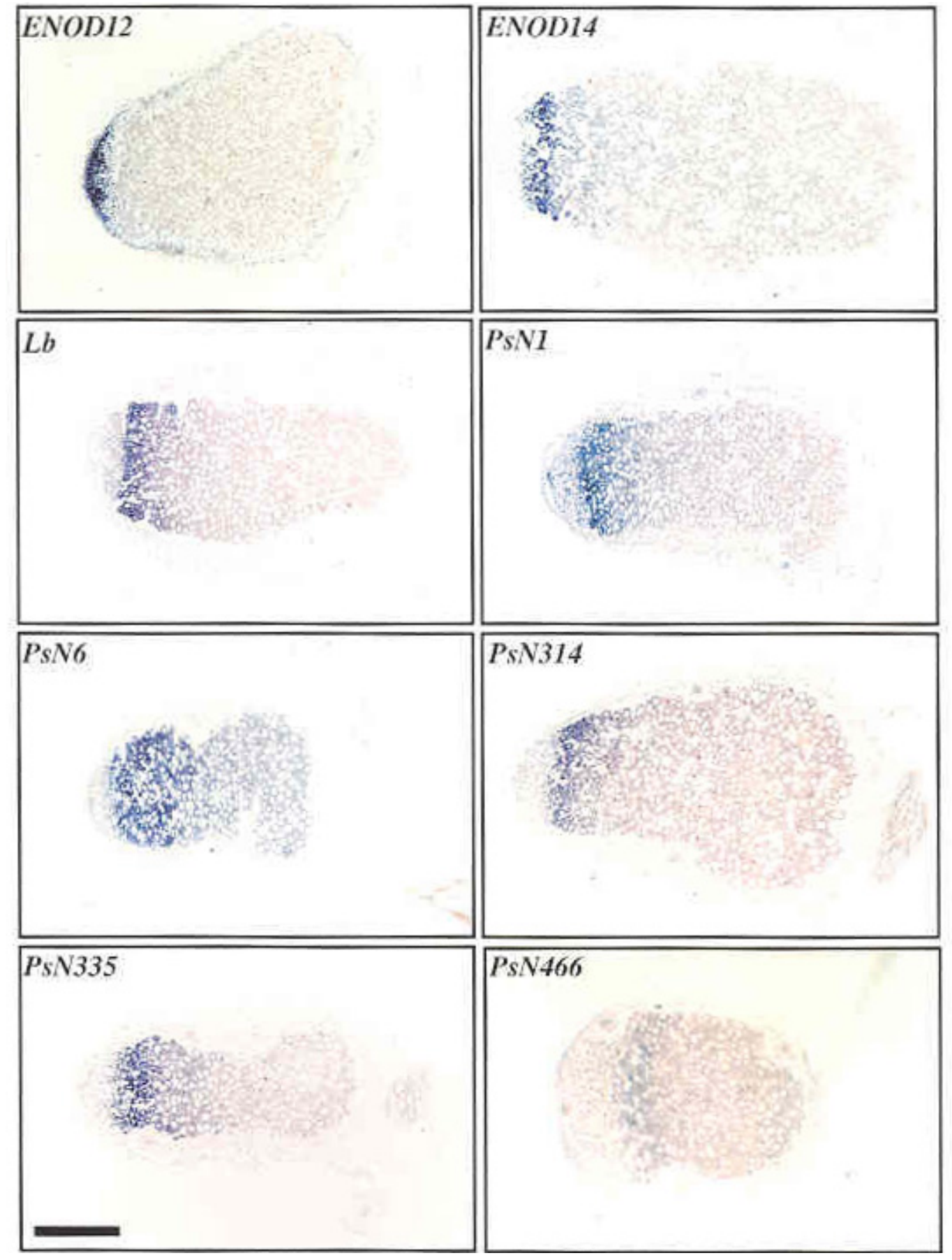

Fig. 5. In situ localization of mRNA for $P s N 1, P s N 6, P s N 314, P s N 335$, and $P s N 466$ in effective cv. Sparkle nodules. Nodules were harvested from 4week-old plants. ENOD12, ENOD14, and leghemoglobin (Lb) were used for reference. Longitudinal sections $(10 \mu \mathrm{m})$ through the nodules were hybridized with digoxigenin-labeled antisense probes. Hybridization signals are visible as purple or blue. No significant signals were detected by any sense probe (data not shown). The bar represents $500 \mu \mathrm{m}$, and all micrographs were taken at the same magnification. 
likely that the expression of PSNOD6 will be reduced in ineffective E135 nodules. Furthermore, PsNOD10 or PsNOD14 might be identical to one of the nodulin genes PsN1, PsN6, PsN314, PsN335, or PsN466.

Genomic Southern analysis of PsN1, PsN6, PsN314, $P s N 335$, and $P s N 466$ showed multiple bands (Fig. 3). Since we isolated incomplete cDNA clones containing a few base pair changes for $P s N 1, P s N 314, P s N 335$, and $P s N 466$ in this study (data not shown), each of the multiple genes is thought to be actually expressed. Therefore, it is probable that nodulins characterized by a putative signal peptide and conserved cysteine residues are abundant in pea nodules. Including the early nodulin genes ENOD3 and ENOD14, at least 15 genes encod- ing this class of nodulin are predicted to be present in the pea genome. Recently, Frühling and associates (2000) isolated five late nodulin genes encoding CCPs that show similar features in V. faba (Fig. 1). In addition, a similar nodulin gene in Galega orientalis has been submitted to the DNA database (accession number AJ133497). These data indicate that this class of nodulins is generally present in the nodules. It is notable in studying the origin of this type of nodulin gene that these nodulins are structurally homologous, but similarities of entire amino acid sequences are relatively low (Fig. 1). This contrasts with the Lb genes that form a large gene family.

Transcripts of PsN1, PsN6, PsN314, PsN335, and PsN466 were restricted to the infected cell type (Fig. 7), indicating that

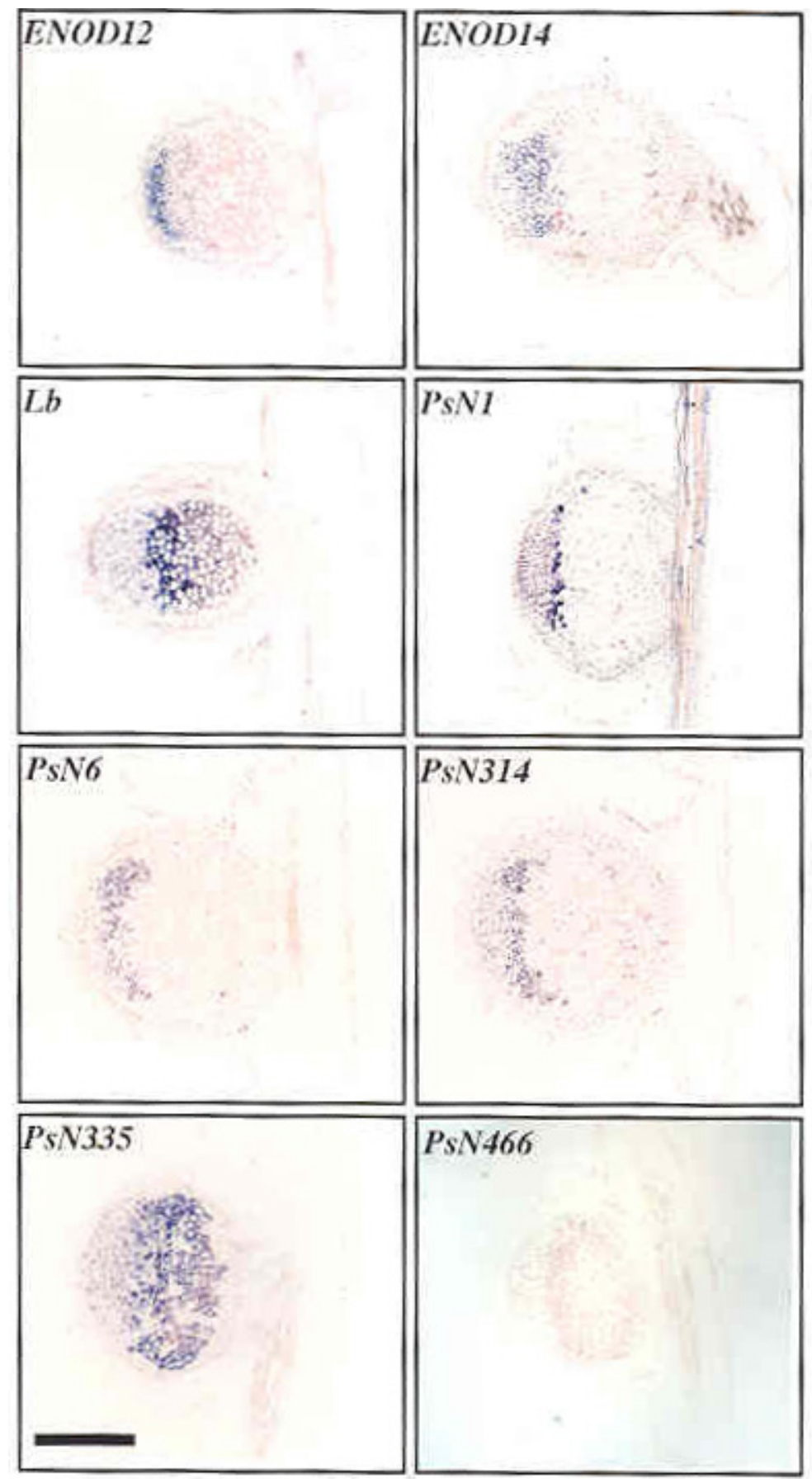

Fig. 6. In situ localization of mRNA for PsN1, PsN6, PsN314, PsN335, and PsN466 in ineffective E135 nodules. Nodules were harvested from 4-week-old plants. ENOD12, ENOD14, and leghemoglobin $(\mathrm{Lb})$ were used for reference. Longitudinal sections $(10 \mu \mathrm{m})$ through the nodules were hybridized with digoxigenin-labeled antisense probes. Hybridization signals are visible as purple or blue. No significant signals were detected by any sense probe (data not shown). The bar represents $500 \mu \mathrm{m}$, and all micrographs were taken at the same magnification. 
rhizobial invasion is a prerequisite for induction of their expression. Furthermore, their transcripts were detected predominantly from the interzone II-III to the distal part of nitrogenfixing zone III (Fig. 5), consistent with that of the late nodulin gene PsNOD6 (Kardailsky et al. 1993). However, PsN6 expressed slightly earlier and PsN466 later on the basis of temporal and spatial expression patterns (Figs. 4 and 5). These results suggest that they are differentially regulated. Frühling and associates (2000) examined the spatial expression patterns of five late nodulin genes encoding CCPs by tissue print hybridizations. They also showed that the distribution patterns of their transcripts are varied, suggesting that their regulation involves different mechanisms.

In ineffective E135 nodules, transcripts of PsN1, PsN6, $P s N 314, P s N 335$, and $P s N 466$ were detected in narrower regions compared with transcripts in effective nodules (Figs. 5 and 6). Therefore, reductions in expression of these nodulin genes in ineffective E135 nodules by northern analysis (Suganuma et al. 1995) are ascribed to the limited distribution of their transcripts. These results are consistent with the case of Lb gene PsN5, although reductions in the expression regions of the five nodulin genes in ineffective nodules were not as remarkable as that of PsN5 (Kawashima et al. 2001). It is likely that the expression of these late nodulin genes is induced without nitrogenase activity, but nitrogenase activity is required for successive expression of their nodulin genes during nodule development.

The problem is to determine the function of this class of nodulins and to identify the target of a putative signal peptide. The expression of early nodulin genes PSENOD3 and PsENOD14 is not affected in ineffective E135 nodules, whereas the expression of late nodulin genes PsN1, PsN6, PsN314, PsN335, and PsN466 is reduced (Table 1 and Fig. 6). This may indicate that they are functionally different depending on the time of appearance during nodule development, although they contain the common structures of two cysteine clusters. The conserved cysteine residues may bind to a metal ion. Scheres and associates (1990) assumed that they have a role in the transport of metals over the peribacteroid membrane to the bacteroid, because the bacteroids require molybdenum and iron for the synthesis of nitrogenase. This might explain findings that the transcripts of late nodulin genes were localized from the interzone II-III and the distal part of nitrogen-fixing zone III, where nitrogen-fixing activity begins to appear, and that their expression regions were restricted to narrower cell layers in ineffective E135 nodules (Figs. 5 and 6). In addition, a large amount of iron is required for Lb. In ineffective E135 nodules, the levels of heme were considerably lower than those in effective nodules (Suganuma et al. 1995) while the levels of iron in ineffective nodules were similar to those in effective nodules (N. Suganuma, unpublished data). Moreover, the spatial expression patterns of those late nodulin genes resembled those of the Lb gene in effective nodules (Fig. 5). These results may suggest that this class of late nodulins is concerned with transport of iron for heme of Lb. Otherwise, there is a possibility that the formation of disulfide bonds by this class of nodulins may be subject to redox control in nodule tissue. Moran and associates (2000) showed that legume nodules contain large amounts of the thiol tripeptides glutathione and homoglutathione and that they play critical roles for nodule functioning. In contrast, the transcripts of PsENOD3/14 are detected in the pre-fixing zone II of pea nodules (Scheres et al. 1990) and their expression in ineffective E135 nodules was comparable to that in the effective nodules (Figs. 5 and 6) (Suganuma et al. 1995). It might be possible that these early nodulins are related mainly to rhizobial infection into nodule cells or proliferation of symbiosomes and that the cysteine resi- dues act to form disulfide bridges after secretion for certain components.

Although several nodulins proposed to code for peribacteroid membrane proteins have been isolated from soybean nodules, it is not known how proteins are targeted to the peribacteroid membrane, and a signal sequence specific to the peribacteroid membrane has not been identified (Whitehead and Day 1997). Significant similarities in the putative signal sequences are not found between peribacteroid membrane nodulins and nodulins containing conserved cysteine clusters shown in Figure 1. Identification of the target of their putative signal peptides would help greatly for elucidating the functions of these nodulins.

\section{MATERIALS AND METHODS}

\section{Plant materials.}

The seeds of the parental pea (Pisum sativum L. cv. Sparkle) and the Fix ${ }^{-}$mutant E135 (sym13) derived from it (Kneen et al. 1990) were surface-sterilized and inoculated with Rhizobium leguminosarum bv. viciae strain 128C53. The plants were grown in vermiculite with a nitrogen-free nutrient solution in a greenhouse under natural daylight, as described previously (Suganuma et al. 1993).

\section{cDNA cloning and sequence analysis.}

cDNA clones that had been isolated by a subtractive hybridization procedure (Suganuma et al. 1995) did not have complete protein-coding regions. Therefore, recombinant phages derived

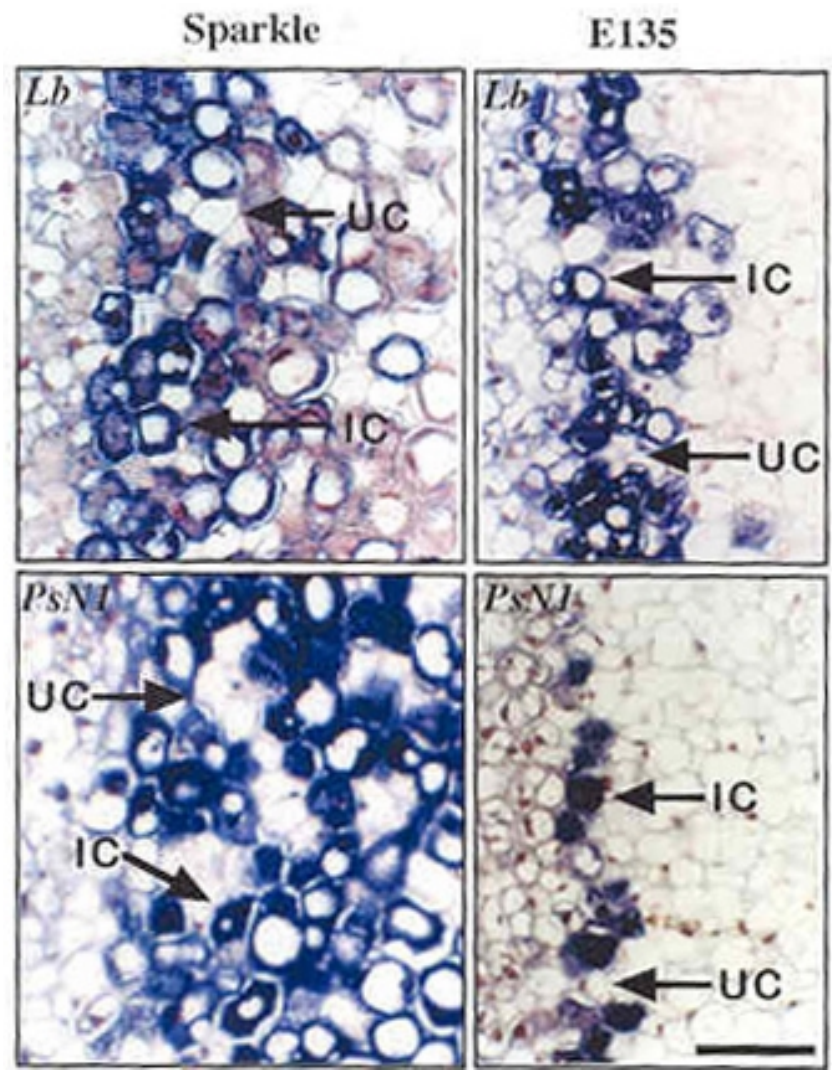

Fig. 7. In situ localization of mRNA for $P_{s} N 1$ in the central part of effective cv. Sparkle nodules and ineffective E135 nodules. Nodules were harvested from 4-week-old plants. Leghemoglobin ( $\mathrm{Lb}$ ) were used for reference. Longitudinal sections $(10 \mu \mathrm{m})$ through the nodules were hybridized with digoxigenin-labeled antisense probes. Hybridization signals are visible as purple or blue. The bar represents $100 \mu \mathrm{m}$ and all micrographs were taken at the same magnification. $\mathrm{IC}=$ infected cell; $\mathrm{UC}=$ uninfected cell. 
from a $\lambda$ gt10 cDNA library constructed from poly $(\mathrm{A})^{+}$RNA of nodules of 5-week-old cv. Sparkle plants were rescreened with each cDNA insert as a probe. Since the cDNA clones containing the entire coding region for PsN1 and PsN335 were not obtained by rescreening, the $5^{\prime}$ RACE system (Gibco-BRL, Rockville, MD, U.S.A.) was used to obtain their $5^{\prime}$-upstream sequences. Isolated cDNA inserts from positive recombinants or amplified cDNAs were subcloned into pBluescript II SK(+) (Stratagene, La Jolla, CA, U.S.A.) and their nucleotide sequences were determined with an automatic ABI PRISM 310 sequencer (Applied Biosystems, Foster City, CA, U.S.A.). Nucleotide and deduced amino acid sequences were analyzed with the GeneWorks program (Intelligenetics, Mountain View, CA, U.S.A.). Multiple sequence alignment was carried out using the CLUSTAL W program (Thompson et al. 1994) of the DNA Data Bank of Japan (Mishima, Japan). Predictions of signal peptides and their cleavage sites were performed with the SignalP program (Nielsen et al. 1997).

\section{Southern and northern blot analyses.}

Genomic DNA was isolated from the leaves of 3-week-old cv. Sparkle plants according to the method of Murray and Thompson (1980). Genomic DNA was digested to completion with BamHI, EcoRI, and HindIII. Total RNAs were isolated from various tissues of cv. Sparkle plants or nodules harvested from cv. Sparkle plants at different days after inoculation by phenol extraction and $\mathrm{LiCl}$ precipitation (Suganuma et al. 1995). DNA fragments were separated on a $0.8 \%$ (wt/vol) agarose gel, and total RNAs were subjected to electrophoresis on a $1.25 \%(\mathrm{wt} / \mathrm{vol})$ agarose gel that contained formaldehyde and transferred to a Hybond-N membrane (Amersham Pharmacia Biotech, Uppsala, Sweden) according to standard procedures (Sambrook et al. 1989). DNA probes were prepared from each cDNA insert with ${ }^{32} \mathrm{P}$-dCTP and a BcaBEST Labeling Kit (TaKaRa, Kyoto, Japan). PsN2 (ENOD2; Suganuma et al. 1995) and PsLb120-1 (Kawashima et al. 2001) were used for reference as the early and late nodulin genes. Hybridization and washing were done as described previously (Suganuma et al. 1997).

\section{In situ hybridization.}

In situ hybridization was performed as described by Kouchi and Hata (1993). RNA probes were prepared from linearized plasmids with digoxigenin-11-UTP (Roche Diagnostics, Basel, Switzerland), and the hybridization signals were detected by antidigoxigenin-alkaline phosphatase conjugate with nitroblue tetrazolium salt and 5-bromo-4-chloro-3-indolyl phosphate toluidinium salt (Roche Diagnostics, Basel, Switzerland). ENOD12 cDNA was previously prepared by amplification by polymerase chain reaction (Suganuma et al. 1995). PsN35 (ENOD14) and PsLb120-1 were also used for reference.

\section{ACKNOWLEDGMENTS}

This work was supported by special coordination funds for promoting science and technology from the Japanese Ministry of Education, Culture, Sports, Science, and Technology. The authors thank T. A. LaRue for critically reading the manuscript.

\section{LITERATURE CITED}

Altschul, S. F., Madden, T. L., Schaffer, A. A., Zhang, J., Zhang, Z., Miller, W., and Lipman, D. J. 1997. Gapped BLAST and PSI-BLAST: A new generation of protein database search programs. Nucleic Acids Res. 25:3389-3402.

Baulcombe, D., and Verma, D. P. S. 1978. Preparation of a complementary DNA for leghaemoglobin and direct demonstration that leghaemoglobin is encoded by the soybean genome. Nucleic Acids Res. 5:4141-
4153.

Bergmann, H., Preddie, E., and Verma, D. P. S. 1983. Nodulin-35: A subunit of a specific uricase (uricase II) induced and localized in the uninfected cells of soybean nodules. EMBO (Eur. Mol. Biol. Organ.) J. 2:2333-2339.

Dunn, K., Dickstein, R., Feinbaum, R., Burnett, B. K., Peterman, T. K., Thoidis, G., Goodman, H. M., and Ausubel, F. M. 1988. Developmental regulation of nodule-specific genes in alfalfa root nodules. Mol. Plant-Microbe Interact. 1:66-74.

Frühling, M., Albus, U., Hohnjec, N., Geise, G., Pühler, A., and Perlick, A. M. 2000. A small gene family of broad bean codes for late nodulins containing conserved cysteine clusters. Plant Sci. 152:67-77.

Gebhardt, C., Oliver, J. E., Forde, B. G., Saarelainen, R., and Miflin, B. J. 1986. Primary structure and differential expression of glutamine synthetase genes in nodules, roots, and leaves of Phaseolus vulgaris. EMBO (Eur. Mol. Biol. Organ.) J. 5:1429-1435.

Govers, F., Nap, J.-P., Moerman, M., Franssen, H. J., van Kammen, A., and Bisseling, T. 1987. cDNA cloning and developmental expression of pea nodulin genes. Plant Mol. Biol. 8:425-435.

Jiménez-Zurdo, J. I., Frugier, F., Crespi, M. D., and Kondorosi, A. 2000. Expression profiles of 22 novel molecular markers for organogenetic pathways acting in alfalfa nodule development. Mol. Plant-Microbe Interact. 13:96-106.

Kardailsky, I., Yang, W.-C., Zalensky, A., van Kammen, A., and Bisseling, T. 1993. The pea late nodulin gene PsNOD6 is homologous to the early nodulin genes PsENOD3/14 and is expressed after the leghaemoglobin genes. Plant Mol. Biol. 23:1029-1037.

Kardailsky, I. V., Sherrier, D. J., and Brewin, N. J. 1996. Identification of a new pea gene, PsNlec1, encoding a lectin-like glycoprotein isolated from the symbiosomes of root nodules. Plant Physiol. 111:49-60.

Kawashima, K., Suganuma, N., Tamaoki, M., and Kouchi, H. 2001. Two types of pea leghemoglobin genes showing different $\mathrm{O}_{2}$-binding affinities and distinct patterns of spatial expression in nodules. Plant Physiol. 125:641-651.

Kneen, B. E., LaRue, T. A., Hirsch, A. M., Smith, C. A., and Weeden, N. F. 1990. sym 13-A gene conditioning ineffective nodulation in Pisum sativum. Plant Physiol. 94:899-905.

Kouchi, H., and Hata, S. 1993. Isolation and characterization of novel nodulin cDNAs representing genes expressed at early stages of soybean nodule development. Mol. Gen. Genet. 238:106-119.

Kozik, A., Matvienko, M., Scheres, B., Paruvangada, V. G., Bisseling, T., van Kammen, A., Ellis, T. H. N., LaRue, T., and Weeden, N. 1996. The pea early nodulin gene PsENOD7 maps in the region of linkage group I containing sym 2 and leghaemoglobin. Plant Mol. Biol. 31:149-156.

Küster, H., Perlick, A. M., and Pühler, A. 1994. Members of a broadbean nodulin family with partial homologies to the alfalfa nodulin 25 are composed of two types of amino acid repeats flanked by unique amino acid sequence termini. Plant Mol. Biol. 24:143-157.

Moran, J. F., Iturbe-Ormaetxe, I., Matamoros, M. A., Rubio, M. C., Clemente, M. R., Brewin, N. J., and Becana, M. 2000. Glutathione and homoglutathione synthetases of legume nodules. Cloning, expression, and subcellular localization. Plant Physiol. 124:1381-1392.

Murray, M. G., and Thompson, W. F. 1980. Rapid isolation of high molecular weight plant DNA. Nucleic Acids Res. 8:4321-4325.

Nap, J.-P., and Bisseling, T. 1990. Developmental biology of a plant-prokaryote symbiosis: The legume root nodule. Science 250:948-954.

Nielsen, H., Engelbrecht, J., Brunak, S., and von Heijne, G. 1997. Identification of prokaryotic and eukaryotic signal peptides and prediction of their cleavage sites. Protein Eng. 10:1-6.

Padilla, J. E., Miranda, J., and Sánchez, F. 1991. Nodulin regulation in common bean nodules induced by bacterial mutants. Mol. PlantMicrobe Interact. 4:433-439.

Rivers, R. L., Dean, R. M., Chandy, G., Hall, J. E., Roberts, D. M., and Zeidel, M. L. 1997. Functional analysis of nodulin 26, an aquaporin in soybean root nodule symbiosomes. J. Biol. Chem. 272:1625616261 .

Sambrook, J., Fritsch, E. F., and Maniatis, T. A. 1989. Molecular Cloning: A Laboratory Manual. 2nd ed. Cold Spring Harbor Laboratory, Cold Spring Harbor, NY, U.S.A.

Scheres, B., van Engelen, F., van der Knaap, E., van de Wiel, C., van Kammen, A., and Bisseling, T. 1990. Sequential induction of nodulin gene expression in the developing pea nodule. Plant Cell 2:687-700.

Schröder, G., Frühling, M., Pühler, A., and Perlick, A. M. 1997. The temporal and spatial transcription pattern in root nodules of Vicia faba nodulin genes encoding glycine-rich proteins. Plant Mol. Biol. 33:113123.

Sengupta-Gopalan, C., Pits, J. W., Thompson, D. V., and Hoffman, L. M. 1986. Expression of host genes during root nodule development in soybean. Mol. Gen. Genet. 203:410-420.

Suganuma, N., Tamaoki, M., and Takaki, M. 1993. Comparison of the 
protein composition and enzymatic activities during development between effective and plant-determined ineffective nodules in pea. Plant Cell Physiol. 34:781-788.

Suganuma, N., Tamaoki, M., and Kouchi, H. 1995. Expression of nodulin genes in plant-determined ineffective nodules of pea. Plant Mol. Biol. 28:1027-1038.

Suganuma, N., Okada, Y., and Kanayama, Y. 1997. Isolation of a cDNA for nodule-enhanced phosphoenolpyruvate carboxylase from pea and its expression in effective and plant-determined ineffective pea nodules. J. Exp. Bot. 48:1165-1173.

Suganuma, N., Sonoda, N., Nakane, C., Hayashi, K., Hayashi, T., Tamaoki, M., and Kouchi, H. 1998. Bacteroids isolated from ineffective nodules of Pisum sativum mutant E135 (sym13) lack nitrogenase activity but contain the two protein components of nitrogenase. Plant Cell Physiol. 39: 1093-1098.

Thummler, F., and Verma, D. P. S. 1987. Nodulin-100 of soybean is the subunit of sucrose synthase regulated by the availability of free heme in nodules. J. Biol. Chem. 262:14730-14736.

Thompson, J. D., Higgins, D. G., and Gibson, T. J. 1994. CLUSTAL W: Improving the sensitivity of progressive multiple sequence alignment through sequence weighting, positions-specific gap penalties and weight matrix choice. Nucleic Acid Res. 22:4673-4680.

van Kammen, A. 1984. Suggested nomenclature for plant genes involved in nodulation and symbiosis. Plant Mol. Biol. Rep. 2:43-45.

Whitehead, L. F., and Day, D. A. 1997. The peribacteroid membrane. Physiol. Plant. 100:30-44. 